\title{
VALIDATION OF A HEATING SYSTEM IN THE FARROWING HOUSE USING A CFD APPROACH
}

\author{
Flávio A. Damasceno ${ }^{1 *}$, Carlos E. A. Oliveira ${ }^{2}$, Jairo A. O. Saraz ${ }^{3}$, Leonardo Schiassi², \\ Jofran L. de Oliveira ${ }^{4}$
}

${ }^{1 *}$ Corresponding author. Universidade Federal de Lavras/ Lavras - MG, Brasil. E-mail: flavio.damasceno@deg.ufla.br

\section{KEYWORDS}

Swine, computational modelling, simulation.

\begin{abstract}
The current heating system for piglets in the farrowing usually uses incandescent lamps and, in some cases, heated floors with electric resistances, which in most cases generates a high energy cost. Thus, the implantation of systems that use renewable energies in the heating of piglets can allow the thermal comfort of the animals without reducing the productive development. The objective of this research was to evaluate a computer model in Computational Fluid Dynamics (CFD), which predicts surface temperature in the heating system of a farrowing house. The study was conducted during the summer season on the swine sector of Federal University of Lavras, Brazil. For this study, a prototype solar heater using alternative materials (ASWH) was developed and compared with a conventional solar water heater $(\mathrm{CSWH})$. Two floors were built of cement to test both heating systems and four thermocouple sensors (K type) with digital display were used in each system to test and evaluate the heating efficiency. Based on the results, the average surface temperature in the ASWH and the CSWH treatments was $27.9 \pm 2.6^{\circ} \mathrm{C}$ and $27.1 \pm$ $1.9{ }^{\circ} \mathrm{C}$, respectively. Therefore, the experimental data showed no significant differences from the data obtained by the model, enabling the conclusion that it is suitable for predicting the thermal conditions of this type of heating system and could be used in swine factories to predict energy consumption. Thus, this computational model can be used as a useful tool for the design and selection of heating systems used in swine maternity systems.
\end{abstract}

\section{INTRODUCTION}

Pig farming is an activity that requires a lot of dedication from the breeder to achieve good productivity levels and, consequently, satisfactory profits. In the case of farrowing house, this problem is evidenced by coexistence within it of two categories with very different environmental requirements. On the one hand there is the mature pig which must be cooled, and on the other hand, the piglets, which must be heated. The range of thermal environment comfort for the piglets during the first days of life is between 32 and $34{ }^{\circ} \mathrm{C}$ and as sows can be heat stressed above $22{ }^{\circ} \mathrm{C}$ (Johnson \& Marchant-Forde, 2009; Renaudeau et al., 2003).

Traditionally, in order to ensure thermal comfort for piglets, infrared lamps have been placed above a protected area in the creep feeder, not covering the entire length of the lactation bay area, resulting in high power consumption (Silva et al., 2005). Thus, there is a need for individualized attention to the piglets in order to protect them from exposure to temperatures outside their comfort range, which means investing in heating systems of lower cost and greater efficiency.

The simulation of the thermal environment and heating systems for piglets inside the creep feeder can provide the designer and breeder important information to help in decision making, allowing the reduction of time and costs for development and adaptation projects (Saraz et al., 2016; Damasceno et al., 2014).

Given the enormous importance of the production chain for pigs in Brazil, and consequently the imperative need to seek more sustainable solutions that ensure the minimization of the impact of this activity on the environment, the objective of this study is to validate a model using Computational Fluid Dynamics (CFD) that predicts floor surface temperature of pig maternity creep feeders.

\footnotetext{
${ }^{2}$ Universidade Federal de Lavras/ Lavras - MG, Brasil.

${ }^{3}$ Universidad Nacional da Colômbia/ Medellín, Colômbia.

${ }^{4}$ Universidade Federal de Mato Grosso/ Rondonópolis - MT, Brasil.

Received in: 11-21-2016

Accepted in: 6-12-2018
} 


\section{MATERIAL AND METHODS}

\section{Characterization and operating conditions of the heating systems}

The study was conducted during the summer period of 2015 on an experimental pig maternity center at the Federal University of Lavras, in Lavras - MG, Brazil, located at latitude $21^{\circ} 14^{\prime}$ South, longitude $40^{\circ} 00^{\prime} \mathrm{West}$ of Greenwich, at an altitude of $918.84 \mathrm{~m}$ with an average temperature of $19.4^{\circ} \mathrm{C}$, average annual rainfall of 1529.7 $\mathrm{mm}$ and $76.2 \%$ relative humidity.

For this, a solar water heater prototype was built using alternative materials (ASWH) and compared with a conventional solar water heater (CSWH).

The conventional solar water heater (CSWH) had a solar collector glass plate, made of aluminum, with internal fins painted in matte black to absorb radiation and transfer it to internal piping. The components of the thermal reservoir had pipes manufactured with stainless steel and rigid expanded polyurethane.

The prototype of solar water heaters manufactured with alternative materials (ASWH) was built with PVC pipes and connections (1/2" diameter), PET bottles and milk cartons (Tetra Pak ${ }^{\circledR}$ ). Tetra Park ${ }^{\circledR}$ boxes were painted matte black to absorb heat and keep it retained within the bottles, to then be transferred to water through the PVC pipes which were also painted matte black. In the construction of the alternative solar heater prototype 60 bottles of transparent polyethylene terephthalate (PET) of 2 liters were used. Tetra $\mathrm{Pak}^{\circledR}$ boxes were opened at the top and bottom, leaving them flattened. With this, a cutting jig proposed by CELESC (2009) was used to maintain a standard in all boxes.

A

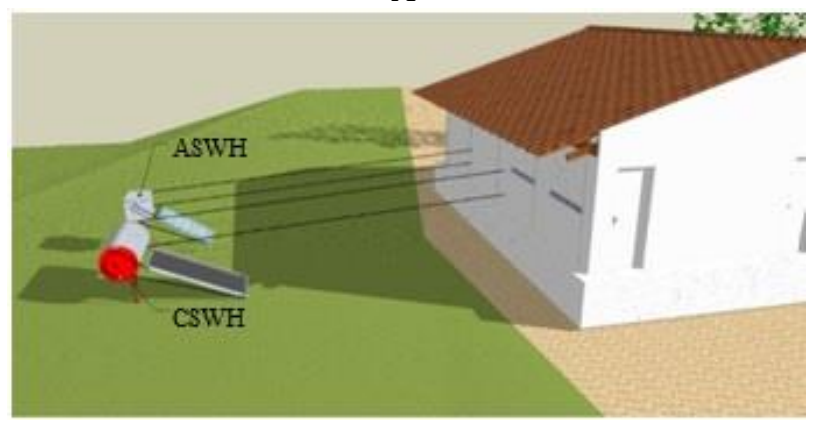

In an alternative construction of the hot water reservoir, a 50 liter fiberglass water tank was used, covered with polystyrene boards $(0.03 \mathrm{~m})$, Silver Tape, and a self-adhesive asphalt and aluminum blanket to protect the polystyrene boards from the weather. Four holes (diameter of $0.02 \mathrm{~m}$ ) were made in the reservoir, two holes being for circulation of water from the thermal reservoir to the solar collector and the other two holes for water circulation from the heat reservoir to the floor.

To test the two water heating systems two floors were built of cement with the dimensions of 0.74 mlength, 0.46 mwidth and 0.07 mthickness. To reduce the heat dissipation at the base of the floors, we used $0.03 \mathrm{~m}$ polystyrene boards. On each floor, a $0.02 \mathrm{~m}$ galvanized steel pipe was placed, forming a coil, to evenly distribute heat from the water inside the floor.

The two solar collectors and water tanks were distanced from the facility about $10 \mathrm{~m}$ to avoid their shading (Figure 1A). A water pump (model ZC-T40, of $12 \mathrm{~V}$ voltage and $1.05 \mathrm{~A}$ ) was used to force the recirculation of water within each system. On each floor, a digital controller was used (thermostat) designed for solar heating applications, which operated to control water flow through the temperature differential between the entrance to the floor and the thermal reservoir.

To test and evaluate the heating efficiency of the two water heating systems four thermocouple sensors ( $\mathrm{K}$ type) with digital display were used in each system, being allocated to the entrance and exit of the heat tank and to the entrance and exit of the floor. The floors were in a creep feeder shelter (Figure 1B). We used an infrared sensor and a thermal camera (Instrutemp ${ }^{\circledR}$, Mod. ITTMV100 and precision $\pm 2 \%$ of the reading) to measure the temperature at the floor surface. The images were processed using the camera's proprietary software from 21 randomly selected points.

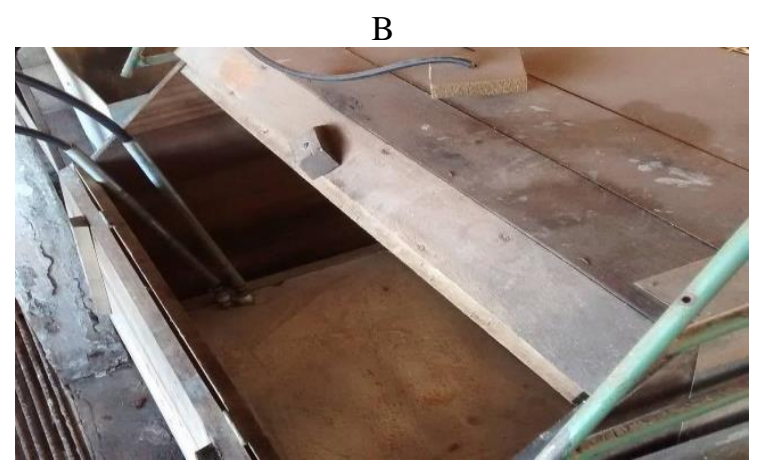

FIGURE 1. Functional diagram of the thermal floor (A) and (B) concrete floor detail inside the creep feeder

\section{Computational model}

The simulation results of this study were obtained from the use of ANSYS ${ }^{\circledR}$. The software and the temporary license for ANSYS $^{\circledR}$ are the property of the Engineering Department of the Federal University of Lavras - Brazil.

Due to the complexity of the geometry, we chose to use the ANSYS ICEM CFD software to build the computational mesh and then the mesh test chosen was the tetrahedral mesh, which had the best results and accorded with the recommendation of Saraz et al. (2013).
The air flow rates are usually associated with turbulent flow and, when combined with the heat transfer interactions, generate a system of equations which is difficult to solve, particularly by non-numeric methods. Thus, the CFD technique used in this study was based on the solution from the average system Reynolds number extracted from the Navier - Stokes, by discretization of the flow field, based on the finite volume technique. The model that describes the flow of fluid is described by the equations of continuity, momentum, and energy, in the following simplified form (Saraz et al., 2016; Mendes et al., 2015; Fluent, 2013; Damasceno et al., 2012): 
$\nabla(\rho \mathrm{U})=0$

$\nabla(\rho U U)=\nabla p+\left[\mu_{\tau}\left(\nabla \mathrm{U}+\nabla \mathrm{U}^{\mathrm{T}}\right)\right]$

$\nabla\left(-\mathrm{k} \nabla \mathrm{t}+\rho \mathrm{C}_{\mathrm{p}} \mathrm{tU}\right)=\mathrm{Q}$

In which,

$\rho$ - density $\left(\mathrm{kg} \mathrm{m}^{-3}\right)$;

$\mathrm{U}$ - velocity vector;

$\mathrm{p}$ - static pressure $\left(\mathrm{N} \mathrm{m}^{-2}\right)$;

$\mu$ - dynamic viscosity of the fluid $\left(\mathrm{kg} \mathrm{m}^{-1} \mathrm{~s}^{-1}\right)$;

T - Tensor transposition;

$\mathrm{k}$ - turbulent kinetic energy $\left(\mathrm{m}^{2} \mathrm{~s}^{2}\right)$;

$\mathrm{t}$ - temperature $(\mathrm{K})$,

$\mathrm{Q}$ - heat source $\left(\mathrm{W} \mathrm{m}^{-3)}\right.$.

\section{Boundary conditions}

ANSYS CFx software was used to perform the simulation, adopting the following assumptions: transient regime and condition with thermal energy. We adopted as convergence criterion a mean residue of linear systems (RMS, Root Mean Square) less than $10^{-4}$.

To perform the simulation, the following assumptions were made:

a. The thermal conductivity showed no significant changes in any part of the concrete floor; so, the thermal conductivity coefficient was assumed constant (Figure 2);

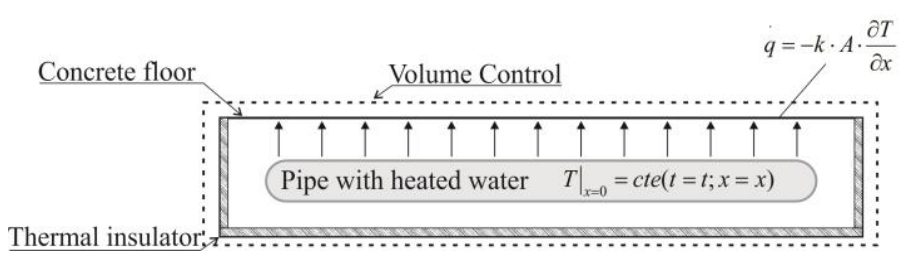

FIGURE 2. Boundary conditions used in the evaluation of underfloor heating.

b. In the concrete floor, heat transfer occurred only by conduction in the solid medium, the transfer of heat between the concrete floor surfaces with ambient air, side and bottom surfaces not being considered;

c. The dimensions and operating conditions of the concrete floor and galvanized steel pipe model were used to generate the CFD model. Thus, the values measured in the experimental phase were used in the boundary conditions in the model, which are listed and presented in Table 1.

TABLE 1 . Means of input values in the boundary conditions for the conventional (CSWH) and alternative (ASWH) heating systems.

\begin{tabular}{|c|c|c|}
\hline System & Input variables & Values \\
\hline \multirow{6}{*}{ CSWH } & Floor temperature & $26.0^{\circ} \mathrm{C}$ \\
\hline & Water temperature within the pipe & $46.7^{\circ} \mathrm{C}$ \\
\hline & Floor material & Concrete \\
\hline & Pipe Material & Galvanized steel \\
\hline & Room temperature & $27.5^{\circ} \mathrm{C}$ \\
\hline & Heat Transfer Coefficient & $0.65 \mathrm{~W} / \mathrm{m}^{2} \mathrm{~K}$ \\
\hline \multirow{6}{*}{ ASWH } & Floor temperature & $26.0^{\circ} \mathrm{C}$ \\
\hline & Water temperature within the pipe & $38.3^{\circ} \mathrm{C}$ \\
\hline & Floor material & Concrete \\
\hline & Pipe Material & Galvanized steel \\
\hline & Room temperature & $27.5^{\circ} \mathrm{C}$ \\
\hline & Heat Transfer Coefficient & $0.65 \mathrm{~W} / \mathrm{m}^{2} \mathrm{~K}$ \\
\hline
\end{tabular}

d. The model did not take into account the presence of animals inside the shelter.

\section{Data analysis}

This study provides a temporal and spatial descriptive analysis of the variables of the floors heated by the alternative and conventional system evaluated. Regressions were performed using the REG procedure in SAS statistical software (version 9.3, SAS Institute, Cary, NC), considering a confidence level of $95 \%$. The results of the CFD model were checked and compared with the corresponding experimental data. The agreement between the values measured and described by the CFD model were evaluated by calculating the normalized mean square of the error (NMSE) recommended by ASTM (2002), and for this a sample was taken of 63 experimental data points for each treatment tested. When you have a lot of correlation between the measured value and the predicted value, the NMSE has value of 0 . Values less than 0.25 of NMSE are accepted as good indicators of agreement, according to ASTM (2002), having been used in several studies to validate computational models (Saraz et al., 2013).

$$
\begin{aligned}
& \mathrm{NMSE}=\frac{\left(\overline{\mathrm{C}_{\mathrm{p}}-\mathrm{C}_{\mathrm{o}}}\right)^{2}}{\left(\mathrm{C}_{\mathrm{pm}} \cdot \mathrm{C}_{\mathrm{om}}\right)} \nabla\left(-\mathrm{k} \nabla \mathrm{T}+\rho \mathrm{C}_{\mathrm{p}} \mathrm{TU}\right)=\mathrm{Q} \\
& \left(\overline{\mathrm{C}_{\mathrm{p}}-\mathrm{C}_{\mathrm{o}}}\right)^{2}=\frac{\sum_{\mathrm{n}}\left(\mathrm{C}_{\mathrm{pi}}-\mathrm{C}_{\mathrm{oi}}\right)^{2}}{\mathrm{n}}
\end{aligned}
$$

In which,

$$
\begin{aligned}
& \mathrm{C}_{\mathrm{pi}} \text { - Predicted value; } \\
& \mathrm{C}_{\mathrm{oi}} \text { - Measured value; } \\
& \mathrm{C}_{\mathrm{pm}} \text { - mean of predicted values; } \\
& \mathrm{C}_{\mathrm{om}} \text { : mean of values measured, } \\
& \mathrm{n} \text { - number of measurements. }
\end{aligned}
$$




\section{RESULTS AND DISCUSSION}

Tests were performed using different ANSYS ICEM CFD ${ }^{\circledR}$ meshes. Different types of tetrahedral meshes were tested and showed no statistical difference $(p<0.05)$ from the level of refinement previously assessed. Thus, the mesh used was composed of 149,503 tetrahedral elements and 32,364 nodes (Figure 3). The tetrahedral mesh used in this study was adaptive from the interior to the boundary, having feature-sensitive on the surface with denser elements in high-curvature regions where geometric feature most likely reside.

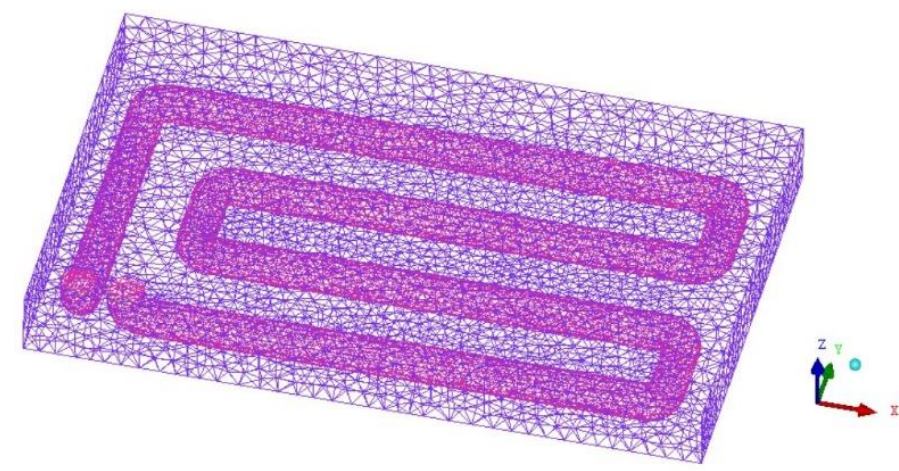

FIGURE 3. Tetrahedral mesh generated for implementation of the CFD model.

The comparison of the data simulated by the CFD model developed with the experimental data shows that the mean temperature values of the floor surface for each treatment tested did not differ significantly between the experimental values and model values, presenting a normalized mean square error (NMSE) for conventional and alternative treatments of 0.002 and 0.0005 , respectively (Table 2). These results indicate excellent agreement between the results, and that the variations found between surface temperatures measured and simulated are due mostly to accuracy errors of the sensor used. Given this, the CFD model can be used to predict the average behavior of the surface temperature in heated floors in maternity pig creep feeders.

Damasceno et al. (2014) using the NMSE to evaluate a heating system in poultry houses using a CFD model, showed NMSE values of 0.25 and 0.02 to CFD model and experimental data of air temperature and speed, respectively. Saraz et al. (2012) validating a CFD model for prediction of the efficiency of evaporative cooling in porous panels, found an NMSE of 0.0009 for data of developed model and experimental data of air temperature. In both cases, the authors claim to have found good results using NMSE.

The values of the surface temperatures of the heated floors by conventional (CSWH) and alternative (ASWH) solar collectors are shown in Figure 4. As can be seen, there is at least a significant difference (t-test, $\mathrm{P}<0.0001)$ between the simulated skin temperature values $\left(\mathrm{T}_{\mathrm{s}}\right)$ of ASWH and CSWH treatments. This is probably due to the lower heating efficiency of the alternative system $(\mathrm{ASWH})$, resulting in lower water temperatures for floor heating.

TABLE 2. Comparison of experimental and simulated data for surface temperature $\left({ }^{\circ} \mathrm{C}\right)$ of the floors heated by conventional (CSWH) and alternative (ASWH) solar collectors.

\begin{tabular}{cccc}
\hline CSWH & Experimental & Surface temperature $\left({ }^{\circ} \mathrm{C}\right)$ & Simulated \\
\hline Mean & 37.2 & 0.016 & 36.9 \\
NMSE & & Surface temperature $\left({ }^{\circ} \mathrm{C}\right)$ & Simulated \\
\hline ASWH & Experimental & & 30.9 \\
\hline NMSE & 31.1 & 0.0005 & \\
\hline
\end{tabular}

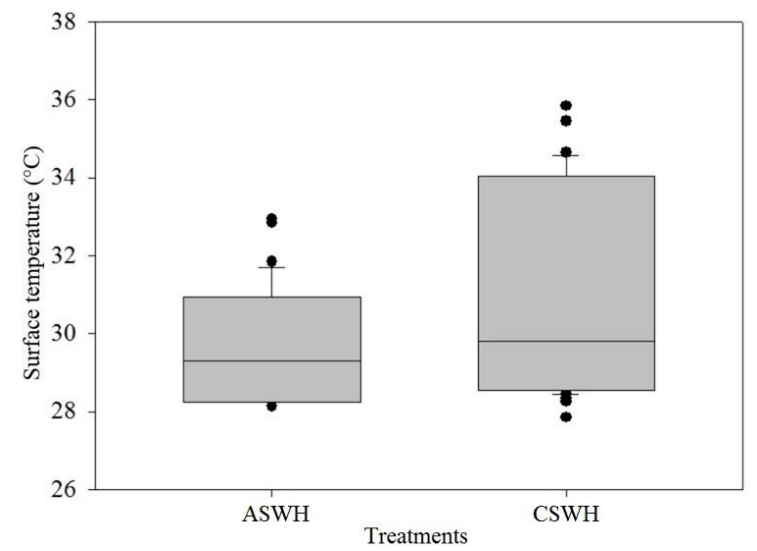

FIGURE 4. Surface temperature variance analysis of the floors heated by conventional (CSWH) and alternative (ASWH) solar collectors.
Thus, two equations were set (Eq. 6 and 7) for determining the simulated surface temperature $\left(\mathrm{T}_{\mathrm{s}}\right)$ for each treatment (CSWH and ASWH), depending on the temperature measured experimentally $\left(\mathrm{T}_{\mathrm{m}}\right)$, Resulting in determining coefficient values $\left(R^{2}\right) 0.677$ and 0.904, respectively. The adjusted equations are statistically significant ( $\mathrm{F}$ test, $\mathrm{P}<0.0001$ ), since a good agreement between the values measured and simulated in all treatments can be observed. Figure 5 illustrates the behavior of the surface temperatures of the floor heated by the CSWH and ASWH solar collectors measured and estimated, resulting in average errors of $0.87 \pm 0.08$ and $0.27{ }^{\circ} \mathrm{C} \pm 0.25{ }^{\circ} \mathrm{C}$ respectively.

$$
\begin{aligned}
& \mathrm{T}_{\mathrm{s}}=0.6710 \mathrm{~T}_{\mathrm{m}}+12.2545 \\
& \mathrm{~T}_{\mathrm{s}}=0.8683 \mathrm{~T}_{\mathrm{m}}+4.34330
\end{aligned}
$$


A

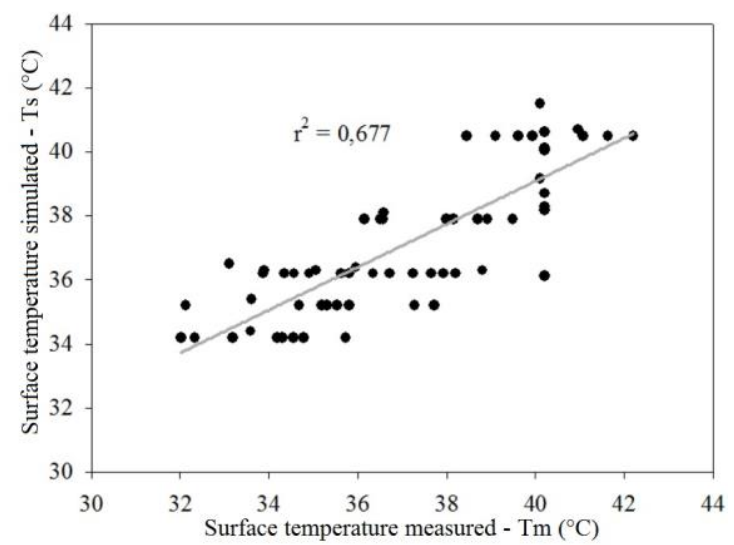

B

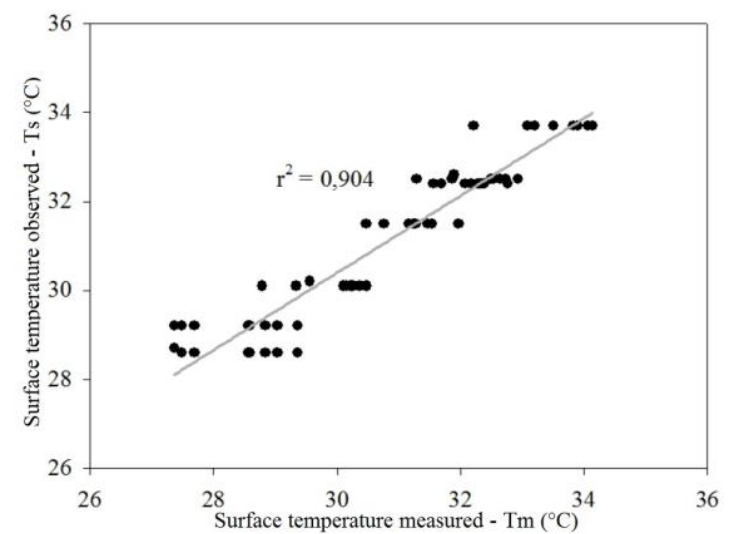

FIGURE 5. Comparison of surface temperature measured $\left(\mathrm{T}_{\mathrm{m}}\right)$ and simulated $\left(\mathrm{T}_{\mathrm{s}}\right)$ on floors heated by solar collectors: Conventional - CSWH (A) and Alternative - ASWH (B).

In Figures 6 and 7 the simulations are presented of the steady state temperature inside and on the surface of floors heated by CSWH and ASWH solar collectors at the initial and final time, respectively.

At the initial time of simulation (Figure 6), the average surface temperature in ASWH and CSWH treatments was $27.9 \pm 2.6{ }^{\circ} \mathrm{C}$ and $27.1 \pm 1.9{ }^{\circ} \mathrm{C}$, respectively. However, it was observed that the time for the floor surface temperature to reach the ideal temperature of $32.0^{\circ} \mathrm{C}$ was 20 minutes for the $\mathrm{CSWH}$ treatment.

A

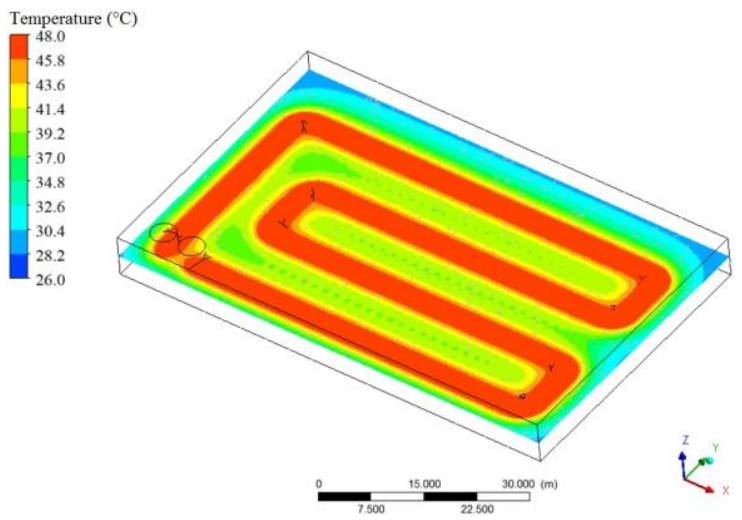

For pigs, the surface temperature values of both treatments simulated were considered thermally comfortable, and the values of the surface temperature of the CSWH treatment were slightly higher in comparison with the results of ASWH treatment (Figure 7).

According to Jeong \& Jung (2015), the heating system with hydraulic underfloor heating needs a longer pre-heating time to reach the desired temperature, as compared with the heating system with electric underfloor heating.

B

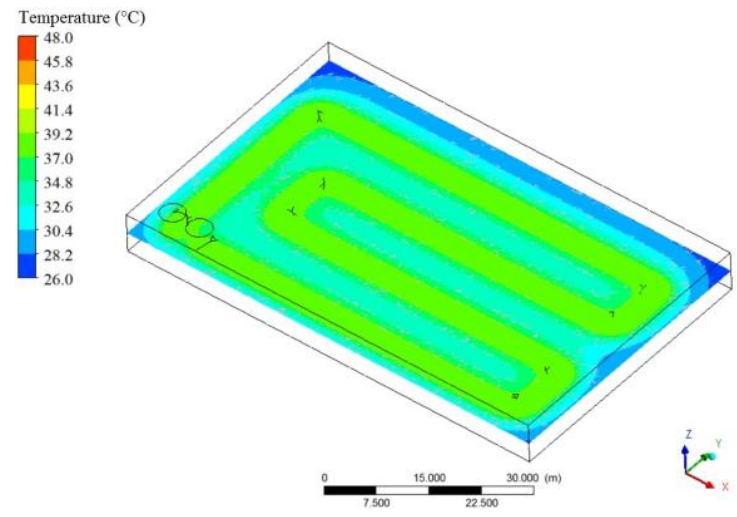

FIGURE 6. Temperature behavior inside the floors heated by solar collectors: Conventional - CSWH (A) and Alternative ASWH (B).

A

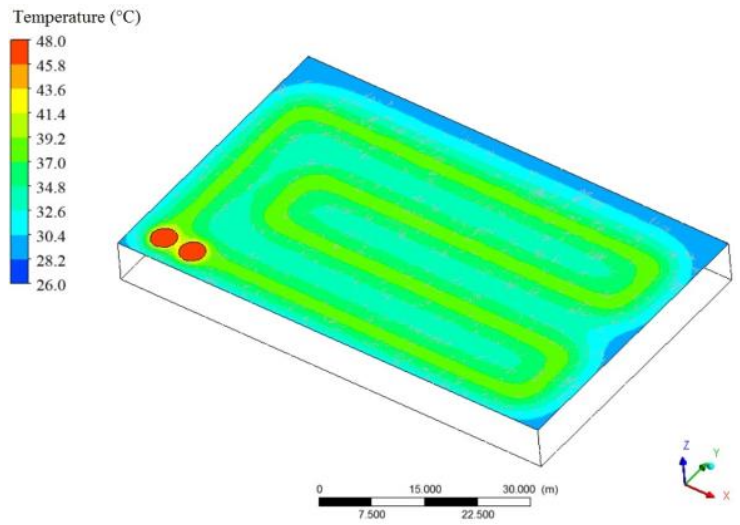

B

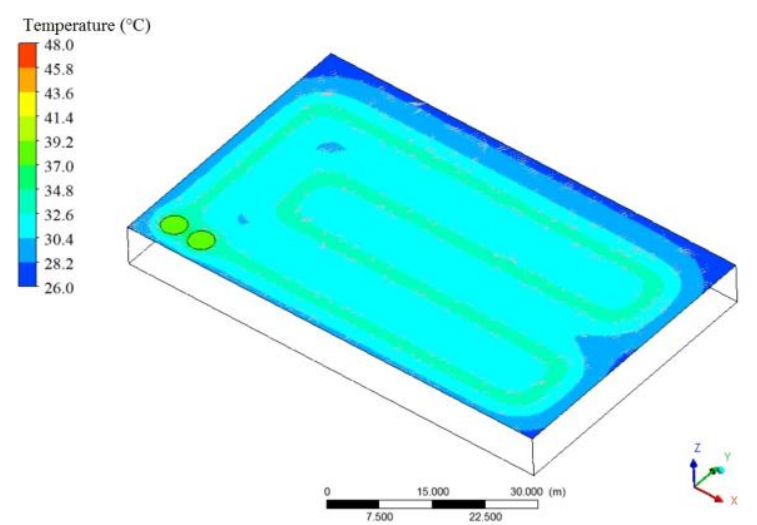

FIGURE 7. Surface temperature behavior of the floors heated by solar collectors: Conventional - CSWH (A) and Alternative ASWH (B). 
The performance of hydraulic underfloor heating can be affected by superimposing any material that changes the heat transfer, which affects the rate of heat input into the conditioned space (Watson \& Chapman, 2002). According to Zhang et al. (2015), the use of underfloor hydraulic heating systems becomes more advantageous if this system is coupled to another renewable source such as solar heating, geothermal energy, etc. The initial cost of the hydraulic floor becomes higher. However, it is more advantageous over the years of

A

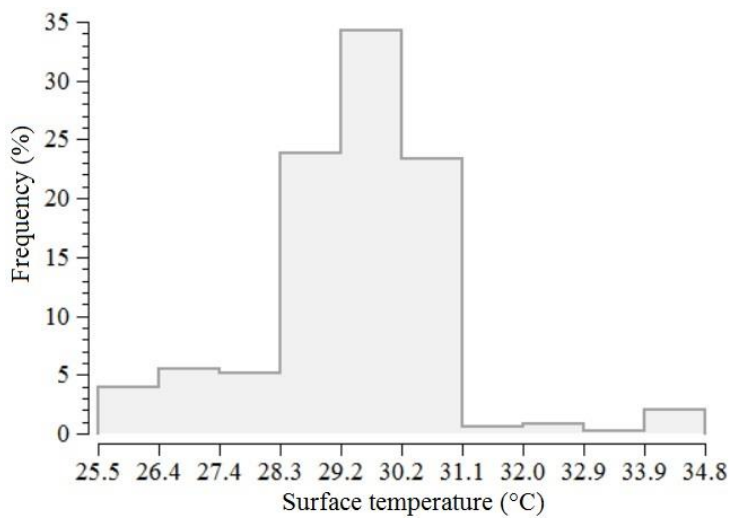

use since, as it does not require high temperatures; heated water from renewable sources can be used directly.

In Figure 8 the frequency of occurrence of the surface temperature of the floors heated by solar collectors in the CSWH and ASWH treatments can be seen. The value of the surface temperature shown in the CSWH treatment was between 28.3 and $31.1{ }^{\circ} \mathrm{C}$. However, in the ASWH treatment, the most evident surface temperature was $29.3{ }^{\circ} \mathrm{C}$, with about $50 \%$ frequency of occurrence.

B

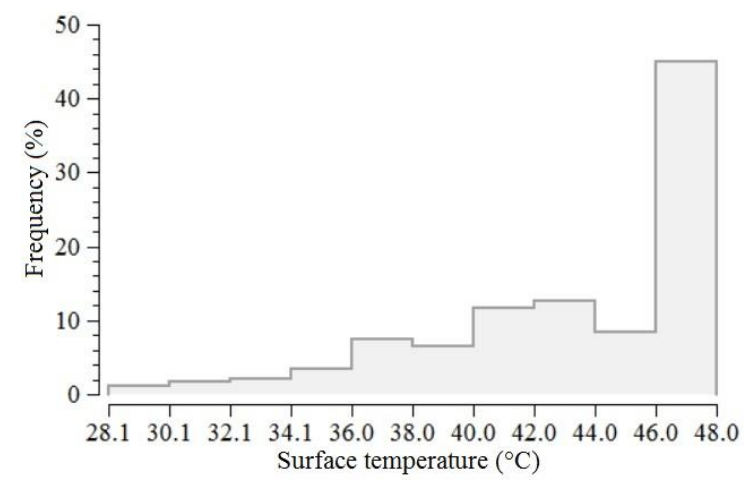

FIGURE 8. Frequency of occurrence (\%) of the temperature behavior on the surface of floors heated by solar collectors: Conventional - CSWH (A) and Alternative - ASWH (B).

\section{CONCLUSIONS}

1. Based on the results, it was found that the different alternative heating systems used were efficient in maintaining the temperature of the floor surface inside the creep feeder shelter within the limits of thermal comfort for the piglets.

2. The proposed CFD computational model showed good statistical correlation with experimental data, which may be used to predict in real time the behavior of the surface temperature on concrete floors heated by the conventional and alternative systems using solar panels. Thus, this computational model can be used as a useful tool for the design and selection of heating systems used in swine maternity systems.

3. The construction of solar collectors using alternative materials stands out for its strong social and environmental nature, due to the construction cost being relatively low and the operation easy and it can be constructed and used by livestock producers for heating purposes, besides the saving in fossil fuel consumption and the reduction in carbon emission.

\section{REFERENCES}

ASTM (2002) Guide for statistical evaluation of indoor air quality models (D5157-97). In: ASTM Standards on Indoor Air quality. West Conshohocken, American Society for Testing Materials. CELESC (2009) Aquecedor solar composto de produto descartáveis - Manual de construção e instalação. Florianópolis, Governo do Estado de Santa Catarina, 44 p. Available in:

http://novoportal.celesc.com.br/portal/images/arquivos/ma nuais/manual-aquecedor-solar.pdf. Accessed: Apr 6, 2016.
Damasceno FA, Saraz JAO, Mendes LB, Martin S, Martins MA (2014) Evaluation of a Heating System in Poultry Houses Using a CFD Model. Revista Facultad Nacional de Agronomia 67(2):7355-7363.

Damasceno FA, Lopes IM, Day GB, Taraba JL, Baêta FC, Overhults D (2012) Study of natural ventilation in reduced scale model of compost bedded pack barn. In: ASABE Annual International Meeting. Dallas, American Society of Agricultural and Biological Engineers, Proceedings...

Fluent (2013) ANSYS Fluent User's Guide, version 15.0.

Johnson AK, Marchant-Forde JN (2009) Welfare of Pigs in the Farrowing Environment. The Welfare of Pigs 7:141188.

Jeong YS, Jung HK (2015) Thermal Performance Analysis of Reinforced Concrete Floor Structure with Radiant Floor Heating System in Apartment Housing Advances in Materials Science and Engineering 2015:1-7.

Mendes LB, Vogeleer G de, Van Overbeke P, Demeyer P, Pieters JG (2015) Effects of Standard k- $\varepsilon$ and LES Turbulence Models on a Full Scale Numerical CFD Simulation for a Naturally Ventilated Pig Barn Prototype. In: ASABE Annual International Meeting. New Orleans, American Society of Agricultural and Biological Engineers, Proceedings...

Renaudeau D, Noblet J, Dourmad JY (2003) Effect of ambient temperature on mammary gland metabolism in lactating sows. Journal of Animal Science 81:217-231. 
Saraz JAO, Martins MA, Rocha KSO, Machado NS, Velasques HJC (2013) Use of computational fluid dynamics to simulate temperature distribution in broiler houses with negative and positive tunnel type ventilation systems. Revista U.D.C.A Actualidad \& Divulgación Científica 16(1):159-166.

Saraz JAO, Tinôco IFF, Rocha KSO, Martins MA, Damasceno FA (2012) Validation of a CFD model for prediction of the efficiency of evaporative cooling in porous panels. Revista U.D.C.A Actualidad \& Divulgación Científica 15(1):209-217.

Saraz JAO, Tinôco IFF, Rocha KSO, Mendes LB, Norton $\mathrm{T}$ (2016) A CFD based approach for determination of ammonia concentration profile and flux from poultry houses with natural ventilation. Revista Facultad Nacional de Agronomía 69(1):7825-7834.
Silva IJO, Pandorfi H, Piedade SMS (2005) Uso da zootecnia de precisão na avaliação do comportamento de leitões lactentes submetidos a diferentes sistemas de aquecimento. Revista Brasileira de Zootecnia 34(1):220229.

Watson RD, Chapman KS (2002) Radiante heating and cooling handbook. McGraw-Hill Handbooks.

Zhang X, Shen J, Tang L, Yang T, Xia L, Hong Z, Wang L, Wu Y, Shi Y, Xu P, Liu S (2015) Building Integrated Solar Thermal (BIST) Technologies and Their Applications: A Review of Structural Design and Architectural Integration. Fundamentals of Renewable Energy and Applications 5(5):1-21. 